pressure is greater than $104 \mathrm{~mm} \mathrm{Hg}$ on, say, a third examination. The immediate problem is to improve the efficiency of detection and treatment for the benefit of these patients.

${ }^{1}$ Dollery, C T, et al, in A Question of Quality, ed G McLachlan, p 34. London, Oxford University Press, 1976

2 Veterans Administration Cooperative Study Group on Antihypertensive Agents, Fournal of the American Medical Association, 1970, 213, 1143.

${ }^{3}$ Miall, W E, Brennan, P J, and Mann, A H, Clinical Science and Molecular Medicine, 1976, 51, $563 \mathrm{~s}$.

${ }^{4}$ Report of a Cooperative Randomised Controlled Trial, British Medical fournal, 1973, 3, 434.

${ }^{5}$ D'Souza, M F, Swan, A V, and Shannon, D J, Lancet, 1976, 1, 1228.

\section{Pump failure}

The term "pump failure" is rightly popular with clinicians, for it has the merit of simplicity. It came into vogue in the context of acute myocardial infarction to describe the mechanical failure of the damaged heart as distinct from its electrical failure. (In most cases death in acute infarction can be attributed either to extensive myocardial damage, with resulting failure, or to a sudden arrhythmia-ventricular fibrillation or asystole-in a heart that is still contracting well and might long maintain a normal output). But the term may equally be used to describe a chronic state of impaired heart function.

In any group of adults with heart disease the crude cause of cardiac failure can be defined in all but a tiny handful of cases. Coronary disease, with or without hypertension, accounts for the great majority; rheumatic heart valve disease and cor pulmonale for fewer; and congenital heart disease for fewer still. Then come some 50 or more recognised ${ }^{1}$ but rare forms of "myocarditis," and it is only when no specific pathological cause can be identified that recourse is made to the term cardiomyopathy of unknown aetiology.

Age alone is not acceptable as a cause of failure, and the terms senile myocardial degeneration and senile failure are best avoided. ${ }^{2}{ }^{3}$ The same pathological processes affect young and old hearts, though in the elderly failure is more likely to be brought about by a combination of disorders. ${ }^{3}$ The only conditions peculiar to the aged are thought to be the senile form of amyloid ${ }^{4}$ (usually unsuspected clinically) and calcific degeneration of the mitral and aortic valves. ${ }^{3}$ Clinical investigators, however, have accumulated evidence that the aged heart's response to exercise is impaired when assessed by measurement of the maximal heart rate, stroke volume, arteriovenous oxygen difference, and ventricular end-diastolic pressures." The fall-off in performance may reflect changes both in cell chemistry and in the peripheral vascular bed.

The deeper analysis of cardiac failure resembles the peeling of an onion, for beneath the clinical appraisal lies the haemodynamic, and beneath this the microscopic, and beneath this yet again lies the essential biochemical lesion. ${ }^{6}$ In simple terms the left ventricle must fail because contractile elements have been destroyed, because the contractility of some or all fibres has been impaired, or because the co-ordination of contraction has been disturbed. It is the definition of contractility that has proved so difficult. The clinician can study his patient by testing exercise capacity, by measuring the left ventricular ejection time, by ultrasound studies of ventricular dimensions, or by invasive methods that provide him with intracardiac pressures. Of these, the left ventricular end-diastolic pressure for long held pride of place as a measure of ventricular performance, though its limitations were cogently pointed out 15 years ago. ${ }^{8}$ From the left ventricular pressure curve can be derived the rate of rise of pressure, perhaps a more plausible measure of muscle function, though again one not immune to criticism. ${ }^{910}$ Stroke work (ejected volume $\times$ aortic pressure), another widely used measure, is also subject to attack. ${ }^{11}$ These methods are acknowledged as crude indices of contractility by muscle physiologists, who are frustrated that they cannot translate the simple concepts of muscle strip experiments to the intact heart. Here the classical concepts of preload, afterload, and change in contractility do not work and, worse, may be misleading.

The difficulties have been analysed in detail in two complementary reviews, ${ }^{912}$ with their theme that the heart is not a muscle but a muscle pump. The preload (end-diastolic volume) and afterload (aortic pressure) are interrelated and must be dealt with as total load on the heart. This, as seen by a muscle fibre in a contracting ventricular wall, is continually changing. Contractility, an intrinsic quality of the myocardium, should ideally be measurable as a function independent of load. The essence of contractility lies in the three dimensions of force, velocity of shortening, and length, the values of which should be caught in an instant, for time will change them. There is no single measurement of myocardial contractility. The present indices in common use are all partial measurements of the force-velocity-length relationship, and all have limitations. We have yet to wait for a reliable and reproducible test that will tell us if a heart is good or bad.

${ }^{1}$ Hudson, R E B, Cardiovascular Pathology. London, Edward Arnold, 1965.

McKeown, F, Pathology of the Aged. London, Butterworths, 1965.

Pomerance, A, British Heart fournal, 1965, 27, 697.

Pomerance, A, British Heart fournal, 1965, 27, 711.

Gerstenblith, G, Lakatta, E G, and Weisfeldt, $M$ L, Progress in Cardiovascular Diseases, 1976, 19, 1.

"Olson, R E, American fournal of Medicine, 1961, 30, 692.

Olson, R E, Ellenbogen, E, and Iyengar, R, Circulation, 1961, 24, 471

${ }^{8}$ Braunwald, E, and Ross, J, American Fournal of Medicine, 1963, 34, 147

${ }^{9}$ Brutsaert, D L, and Sonnenblick, E H, Progress in Cardiovascular Diseases, 1973, 16, 337.

10 Wallace, A G, Skinner, N S, and Mitchell, J H, American fournal of Physiology, 1963, 205, 30.

11 Blinks, J R, Anesthesiology, 1967, 28, 800

12 Brutsaert, D L, and Paulus, W J, Cardiovascular Research, 1977, 11, 1.

\section{Diagnostic amniocentesis in early pregnancy}

Amniocentesis performed from the 15 th week of pregnancy may allow three main groups of fetal abnormalities to be detected. These include all chromosome anomalies, over 60 inborn errors of metabolism, ${ }^{1}$ and neural tube defects. The last may be diagnosed by confirming that high alpha-fetoprotein concentrations exist in liquor ${ }^{2}{ }^{3}$ as well as in maternal venous blood taken between the 16th and 20th week. Ultrasound may diagnose these defects de novo or confirm their presence, and it can even detect hydrocephalus with a normal sized fetal head. ${ }^{4}$ In addition, the determination of fetal sex may identify either potentially affected males or, perhaps more significantly, potential female carriers of certain X-linked recessive diseases-for example, haemophilia.

The performance of amniocentesis implies a commitment on the part of the doctor and the patient to proceed to abortion if an abnormality is definitely confirmed. Recent advances in

4

